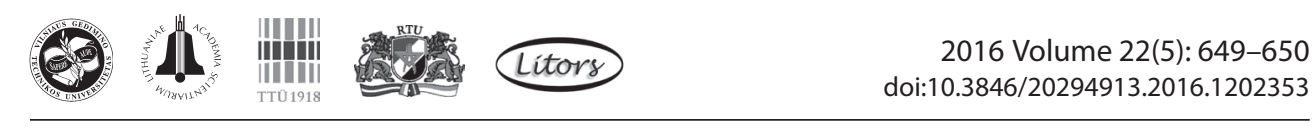

Editorial

\title{
AHP/ANP THEORY AND ITS APPLICATION IN TECHNOLOGICAL AND ECONOMIC DEVELOPMENT: THE 90TH ANNIVERSARY OF THOMAS L. SAATY
}

\author{
Gang KOUª, Daji ERGU ${ }^{\mathrm{b}}$ \\ ${ }^{a}$ School of Business Administration, Southwestern University of Finance and Economics, \\ 610074 Chengdu, China \\ ${ }^{b}$ Southwest University for Nationalities, 610200 Chengdu, China
}

\section{Acknowledgements}

Decision problems with intangible or conflicts muti-criteria usually occur in the real world, and various multi-criteria decision making (MCDM) methods and models have been proposed extensively to handle these problems. The AHP and the ANP, two of the most widely and popularly used MCDM methods have made great contributions to the theories and methodologies of MCDM methods as well as the practical applications in practice. In year 2016, the creator of the AHP/ANP, Professor Thomas L. Saaty will usher in his 90th birthday, thus this special issue aims to celebrate Professor Thomas L. Saaty's 90th birthday and pay generous tributes to his great contribution to the AHP/ANP and decision world.

In addition, we would like to pay our deeply thanks to all the authors for their original papers with high quality to this special issue "AHP/ANP theory and its application in technological and economic development". Also, we would like to give our thanks to all the reviewers who provided valuable comments and suggestions for improving the qualities of this special issue. The guest editor has been partially supported by grants from the National Natural Science Foundation of China (\#71222108), and Major project of the National Social Science Foundation of China (\#15ZDB153). Finally, we would like to thank Professor Edmundas Kazimieras Zavadskas, Editor in Chief of Technological and Economic Development of Economy, for proposing to publish this special issue.

Corresponding author Gang Kou

E-mail: kougang@swufe.edu.cn 


\section{About the papers of this special issue}

In this special issue, five new submissions have contributed to the research field on "AHP/ ANP theory and its application in technological and economic development. The 90th anniversary of prof. Thomas L. Saaty". The contents of the five contributions are briefly summarized in the following.

- Green supplier selection is one of the most important decision making activities to obtain the competitive advantage in a firm. Liao et al. in "Integrated FAHP, ARAS-F and MSGP methods for green supplier evaluation and selection" propose a novel integrated fuzzy techniques for fuzzy analytic hierarchy process (FAHP), fuzzy additive ratio assessment (ARASF) and multi-segment goal programming (MSGP) approach to deal with the green supplier selection problems. In the study, the process of green supplier selection is regarded as a fuzzy multiple criteria decision-making (FMCDM) problem since it involves the qualitative and quantitative criteria. The advantage of the proposed approach is that it allows for the vague segment aspirations of decision makers to set multiple segment aspiration levels for green supplier selection problems.

- Liao et al. in "Integrative model for the selection of a new product launch strategy, based on ANP, TOPSIS and MCGP: a case study" integrate ANP, the technique for order preference by similarity to an ideal solution (TOPSIS) and multi-choice goal programming (MCGP) approach to develop a new approach for the selection of a new product launch strategy. The advantage of the integrated approach is that it is capable of considering the tangible (qualitative) and intangible (quantitative) criteria in the launch strategy of a new product selection problem. Two types of criteria such as "more/higher is better" and "less/lower is better" are also considered in the proposed method.

- In the paper entitled "Combining DRSA decision-rules with FCA-based DANP evaluation for financial performance improvements", by Shen and Tzeng, a combined approach by integrating soft computing techniques (i.e., DRSA) and multiple criteria decision making (MCDM) methods (i.e., DEMATEL and DANP) is proposed to analyze financial performance (FP) of semiconductor companies. The proposed approach can be used to guide semiconductor companies to improve financial performance (FP).

- Shieh et al. in "Critical success factors in digital publishing technology using an ANP approach" develop an evaluation model using analytic network process (ANP) to explore the critical success factors (CSFs) for the successful implementation of Digital publishing technology (DPT). The proposed model can be applied to identify and prioritize the CSFs for the development of DPT. The Taiwan's DPT is used to demonstrate the applicability of the proposed method.

- Kou et al. in "Pairwise comparison matrix in multiple criteria decision making" review the literature of the main developments of the pairwise comparison matrix (PCM), including the measurement scales, consistency indices, inconsistency processing models, missing judgments processing models, priority derivation methods. The reviewed literature were published in the international journal and searched via the ISI Web of science from 2010 to 2015. The results of the review show that the most prevalent research topics in the PCM is cardinal inconsistency processing models, while new approaches remain to be studied for tackling the large dimension and missing judgment under the big data in future. 